
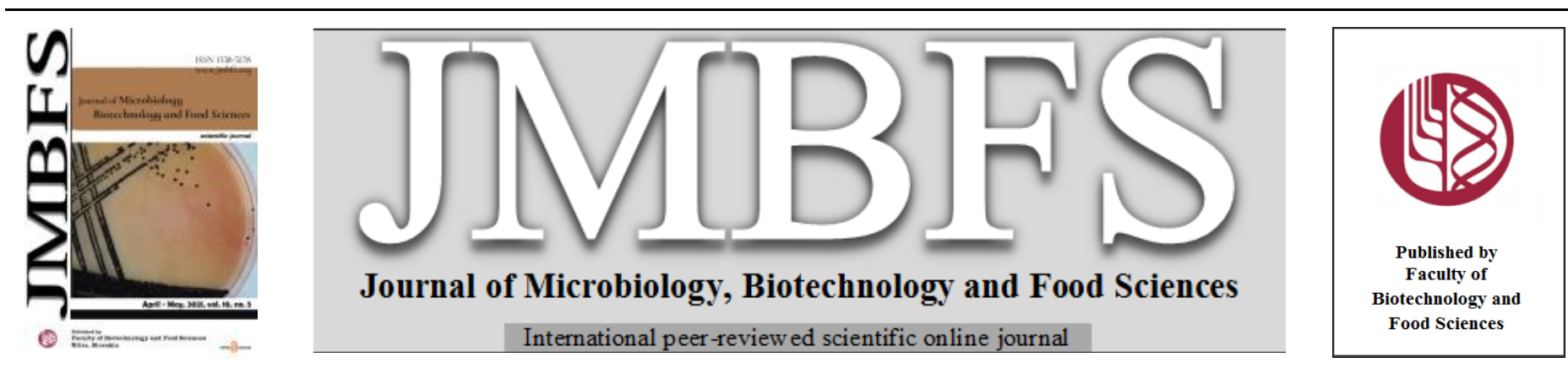

\title{
ANTI-QUORUM SENSING AND ANTITUMOR ACTIVITY OF PRUNELLA VULGARIS, SAMBUCUS NIGRA, CALENDULA OFFICINALIS: potential use in food industry
}

\author{
Melike Nur Tosun ${ }^{1}$, Nükhet Nilüfer Demirel Zorba ${ }^{* 1}$, Yonca Karagül Yüceer ${ }^{1}$ \\ Address(es): \\ ${ }^{1}$ Çanakkale Onsekiz Mart University Engineering Faculty Food Engineering, Çanakkale, Turkey.
}

*Corresponding author: dnukhet@ comu.edu.tr

https://doi.org/10.15414/jmbfs.2774

\section{ARTICLE INFO}

Received 16. 3. 2020

Revised 23. 11. 2020

Accepted 2. 12. 2020

Published 1. 4. 2021

Regular article open $\partial_{\text {Access }}$

\begin{abstract}
With the emergence of health related side effects of synthetic substances, the trend towards natural products has increased and has directed researchers to determine their pharmacological properties. At the same time, the resistance of the microorganisms to the antibiotics used in the treatment revealed that they should be controlled without allowing them to gain resistance. In this study, the total phenolic content, volatile composition and antioxidant, antimicrobial, anti-quorum sensing and antitumor activities of Prunella vulgaris, Sambucus nigra and Calendula officinalis extracts were determined. The antioxidant capacity of the extracts was determined by the Trolox Equivalent Antioxidant Capacity (TEAC) method, volatile component analyses were determined by GC-MS, and antimicrobial activity was determined by the disc diffusion method. Chromobacterium violaceum 026 and Agrobacterium tumefaciens A136 were used to determine the anti-quorum sensing activity. Additionally, the antitumor potential of the extracts was determined by the potato disc method. Prunella vulgaris was the plant with the highest antioxidant capacity, while the extract with the highest antimicrobial activity was determined to be Sambucus nigra against Staphylococcus aureus ATCC 25923. The results showed that all extracts have anti-quorum sensing properties. Prunella vulgaris was the plant with the highest anti-quorum sensing properties. There was a correlation between the extract concentration and tumor inhibition. The Prunella vulgaris extract was found to have the highest antitumor activity. As a result, it was determined that the plants used in the study have the potential to be used in alternative medicine treatment and can be utilized for the control of microorganisms.
\end{abstract}

\section{INTRODUCTION}

The treatment of infectious diseases is based on compounds intended to inhibit or kill microbial growth. Resistance to antibiotics is a severe problem for public health (Bouyahya et al., 2017). Medicinal and aromatic plants have become an essential part of traditional health systems. Phenolic compounds are secondary metabolites with many biological effects, including antioxidant and antimicrobia properties. Studies have shown that these compounds also inhibit bacterial communication. Biofilm formation, bacteriocin production, conjugation, virulence gene expression, pigment production and bioluminescence formation are believed to be regulated by the intercellular communication mechanism known as quorum sensing (QS) in bacteria (Liu et al., 2017). Many types of bacteria use these intercellular signaling mechanisms for a variety of factors, including bacterial pathogenicity and food degradation. Developing new antibacterial drugs based on QS is an attractive strategy to inhibit bacterial growth (Gopu et al., 2015). Plant secondary metabolites and their semisynthetic derivatives play an important role in anticancer drug treatment (Pan et al., 2010). Crown gall is a neoplastic disease caused by Agrobacterium tumefaciens in plants. The Ti plasmid causes the proliferation of plant cells without passing through apoptosis, and the histology is similar to that of human and animal cancers and the nucleic acid content is similar in tumor formation (Islam et al., 2009). That's why researchers use this microorganisms for controlling antitumor mechanisms (Ramezani et al., 2016).

Prunella vulgaris L. (Labiatae) is used in the treatment of sore throat, fever, and wounds in European and Chinese alternative medicine. It is also kown as 'self heal'. (Rasool et al., 2010). Prunella species contain triterpenoids and their saponins, phenolic acids, sterols, and the associated glycosides, flavonoids, organic acids, volatile oils, and saccharides. The active components related to these functions are mainly triterpenoids, phenolic acids, flavonoids, and polysaccharides (Bai $\boldsymbol{e t}$ al., 2016). Pharmacological studies have revealed that Prunella plants possess antibacterial (Mahboubi et al., 2015), antioxidative (Zhang et al., 2011), and antitumor (Hwang et al., 2013) activities.
Sambucus nigra, also called elderberry, is a common species that grows in Europe, Asia, North Africa and America (Veberic et al., 2009). Phenolic groups commonly found in elderberry are anthocyanins, flavonol glycosides, hydroxycinnamic acids, and flavonols (Mikulic-Petkovsek et al., 2015) Anthocyanins and other flavonoids (e.g., quercetin) show antioxidant, anticarcinogenic, immunostimulatory, antibacterial, antiallergic, and antiviral activities. Due to these properties, their consumption can contribute to the prevention of several degenerative diseases, such as cardiovascular disease, cancer, inflammatory diseases, and diabetes (Veberic et al., 2009). Several bioactivities of $S$. nigra have been reported, including antimicrobial (Mohammadsadeghi et al., 2013; Hearts et al., 2010; Hleba et al., 2013), antioxidant (Passos da Silva et al., 2017), and antitumor (Thole et al., 2006) activities.

Calendula officinalis belongs to the Asteraceae family (Chaleshtori et al., 2016), commonly known as the pot marigold, and it is widely cultivated outdoors in warm temperate regions of the world (Larcin $\boldsymbol{e t}$ al., 2016). The traditional medical use of marigold is related to bioactive phytochemicals such as terpenoids, sterols, saponins, carotenoids, and phenolics in the flower extracts (Martin et al., 2016). Many reports have stated that $C$. officinalis extracts have antimicrobial (Cetin et al., 2017) and antioxidant (Mubashar Sabır et al., 2015) activities.

This study aimed to determine the total phenolic content, volatile composition and antioxidant, antimicrobial, anti-quorum sensing and antitumor activities of various extracts obtained from different parts of Prunella vulgaris, Sambucus nigra and Calendula officinalis.

\section{MATERIAL AND METHODS}

Bacterial strains

Staphylococcus aureus ATCC 25923, Staphylococcus aureus RSSK 1009 , Bacillus cereus NCTC 7464, Bacillus subtilis ATCC 6633, Salmonella Typhimurium ATCC 14028, Salmonella Enteritidis ATCC 13076, Escherichia 
coli ATCC 25922, and Escherichia coli ATCC 8739 were supplied by Canakkale Onsekiz Mart University, Faculty of Engineering, Microbiology Laboratory. Agrobacterium tumefaciens A136 and Chromobacterium violaceum 026 were supplied by Prof. Dr. Ji Hyang Kweon, from Konkuk University, Environmental Engineering Faculty.

\section{Plant material}

Prunella vulgaris was collected in June 2015, whereas Sambucus nigra and Calendula officinalis were collected in September 2015. All plants were obtained from Kütahya Municipality Hekim Sinan Medical Plants Research Center. The altitude of this center is 900 meters. Prunella vulgaris and Calendula officinalis were dried at room temperature whereas Sambucus nigra was not dried. Prunella vulgaris was used as a whole plant and milled (Retsch GM 300, Germany) for 30 seconds at 10 -second intervals. The branches and fruit parts of Sambucus nigra were used, and only the flowers of Calendula officinalis were used.

\section{Obtaining the crude extracts}

The previously dried and fruit branched plants were extracted with ethanol and methanol $(1: 10, \mathrm{w} / \mathrm{v})$ at $25^{\circ} \mathrm{C}$ in a shaking incubator (Jeio Tech, IS-971R, Seoul, Korea) at $250 \mathrm{rpm}$ for 8 hours. Extractions were carried out in parallel, and after this time, the liquid parts of the extracts were passed through $0.45 \mu \mathrm{m}$ syringe filters (Sartorius Stedim) and stored at $-18^{\circ} \mathrm{C}$ until analysis.

\section{Trolox equivalent antioxidant capacity (TEAC Assay)}

The antioxidant capacity of extracts obtained with different solvents was determined by TEAC assay (Aydeniz and Yılmaz, 2012). The ABTS radica $(0.0384 \mathrm{~g})$ was dissolved in distilled water in a flask. Two milliliters of 12.25 $\mathrm{mM}$ potassium persulfate (Sigma Aldrich) was added to the dissolved ABTS radical (Sigma Aldrich), and the mixture was diluted to $10 \mathrm{~mL}$ with distilled water. The radical solution $(1 \mathrm{~mL})$ and different concentrations of the extracts were mixed, and the absorbance of each extract was determined at $734 \mathrm{~nm}$ (Shimadzu, UV-1800, Japan). The antioxidant capacities of the extracts were determined using the Trolox equation calibration curve.

\section{Determination of the total phenolic content}

The total phenolic content of the extracts was determined using the FolinCiocalteu reagent (Spanos and Wrolstad, 1990). One hundred microliters of extract, $900 \mu \mathrm{L}$ of distilled water, and $5 \mathrm{~mL}$ of $0,2 \mathrm{~N}$ Folin-Ciocalteu reagent (Sigma Aldrich) were vortexed for 30 seconds. Then, $4 \mathrm{~mL}$ of $\mathrm{Na}_{2} \mathrm{CO}_{3}(75 \mathrm{~g} / \mathrm{L})$ was added to the mixture. The absorbance of the solutions was measured at 750 $\mathrm{nm}$ after 2 hours. Quantitation was expressed as gallic acid equivalents based on the calibration curve.

\section{Determination of volatile compounds by GC-MS}

The volatile components of the extracts were determined by GC-MS (Wilmington DE). The solid-phase microextraction (SPME) technique was used for the isolation of volatile components from the extracts (Nalbant, 2017). Five milliliters of extract and $1 \mathrm{~g}$ of $\mathrm{NaCl}$ were added to a $40 \mathrm{~mL}$ volume vial and incubated at $40^{\circ} \mathrm{C}$ in a water bath for 20 minutes to allow the volatiles in the headspace to equilibrate. The SPME fiber $(2 \mathrm{~cm}-50 / 30 \mu \mathrm{m} \mathrm{DVB})$ was immersed in the vial for 20 minutes under the same conditions. At the end of the extraction period, the fiber was removed from the vial and inserted into the injection port of a GC-MS. GC-MS was performed with an HP-5 capillary column $(30 \mathrm{~m} \times 0,25$ $\mathrm{mm}$ i.d.; film thickness $0,25 \mathrm{um}$ ). The oven temperature was kept at $40^{\circ} \mathrm{C}$ for 2 minutes, increased from $40^{\circ} \mathrm{C}$ to $120^{\circ} \mathrm{C}$ at a rate of $4{ }^{\circ} \mathrm{C} / \mathrm{min}$, held at $120^{\circ} \mathrm{C}$ for 2 minutes, increased from $120-250^{\circ} \mathrm{C}$ at a rate of $8^{\circ} \mathrm{C} / \mathrm{min}$, and held at $250^{\circ} \mathrm{C}$ for 5 minutes. Helium was applied as the carrier gas with a flow rate of $1.50 \mathrm{~mL} / \mathrm{min}$. Identification of the volatile components was performed using the Wiley Registry of Mass Spectral Data (Wiley, 2005) and the National Institute of Standards and Technology (NIST, 2008)

\section{Antibacterial activity assay}

The antibacterial activities of the extracts were determined by the disc diffusion method (Burt and Reinders, 2003). $20 \mu \mathrm{L}$ of plant extracts were loaded onto sterile filter paper discs (6 $\mathrm{mm}$ in diameter, Oxoid), air dried in a laminar flow hood on sterile petri plates, and placed onto Mueller Hinton Agar (MHA, Biolife) plates seeded overnight with 0.5 McFarland cultures of 4 Gram-positive bacteria (S. aureus ATCC 25923, S. aureus RSSK 1009, B. cereus NCTC 7464, and B. subtilis ATCC 6633) and 4 Gram-negative bacteria ( $S$. Typhimurium ATCC 14028, S. Enteritidis ATCC 13076, E. coli ATCC 25922, and E. coli ATCC 8739). Ceftriaxon ( $30 \mu \mathrm{g} / \mathrm{disc}$, Oxoid) was used as a positive control, and ethanol and methanol, the extraction solvents, were used as negative controls. The plates were incubated at $37^{\circ} \mathrm{C}$. After 24 hours, the inhibition zones around the discs were measured and compared with the control groups.

\section{Determination of the minimum inhibitory concentration}

Minimum inhibitory concentrations of the extracts were determined by the microdilution method (Burt and Reinders, 2003). $50 \mu \mathrm{L}$ of Mueller Hinton Broth (Biolife), $50 \mu \mathrm{L}$ of extracts at various concentrations, and $50 \mu \mathrm{L}$ of culture (S. aureus ATCC 25923 , S. aureus RSSK $1009, B$. cereus NCTC 7464, and B. subtilis ATCC 6633, $S$. Typhimurium ATCC 14028, S. Enteritidis ATCC 13076 , E. coli ATCC 25922, and E. coli ATCC 8739) were loaded into 96-well plates. After 18-24 hours of incubation at $37^{\circ} \mathrm{C}$, the absorbance was measured at $450 \mathrm{~nm}$ by a spectrophotometer (Thermo scientific, Multiscan FC, USA). The maximum concentration observed was calculated according to the OD values.

\section{Anti-quorum sensing activity}

The anti-quorum sensing activities of the extracts were determined by the disc diffusion method (McClean et al., 1997; Chenia, 2013). Chromobacterium violaceum 026 (CV026) was used for the determination of short AHLs and inoculated into Luria Bertani Broth containing $50 \mu \mathrm{L}$ of kanamycin $(20 \mathrm{mg} / \mathrm{mL}$, Sigma Aldrich) and incubated at $30^{\circ} \mathrm{C}$ for $24-48$ hours. Agrobacterium tumefaciens A136 was used for the determination of long AHLs and inoculated into Luria Bertani Broth containing $250 \mu \mathrm{L}$ of spectinomycin $(10 \mathrm{mg} / \mathrm{mL}$, Sigma Aldrich) and $50 \mu \mathrm{L}$ of tetracycline $(4,5 \mathrm{mg} / \mathrm{mL}$, Sigma Aldrich) and incubated at $30^{\circ} \mathrm{C}$ for $24-48$ hours. A total of $125 \mu \mathrm{L}$ of overnight culture (CV026) and $20 \mu \mathrm{L}$ of $\mathrm{C}_{6} \mathrm{HSL}$ signal (Sigma Aldrich) were inoculated into Luria Bertani Agar plates. $20 \mu \mathrm{L}$ of X-gal (Acros), $125 \mu \mathrm{L}$ of overnight culture (A. tumefaciens A136), and $20 \mu \mathrm{L}$ of $\mathrm{C}_{8} \mathrm{HSL}$ signal (Sigma Aldrich) were inoculated into Luria Bertani agar plates. $20 \mu \mathrm{L}$ of extracts penetrated paper discs placed in plates. After 24 hours of incubation at $30^{\circ} \mathrm{C}$, zone-forming extracts were detected.

\section{Determination of antitumor activity}

The antitumor activity of the extracts was evaluated using the potato disc assay (Ramezani et al., 2016). Potatoes (Solanum tuberosum L.) were peeled and immersed for 30 minutes in a $1 \%$ hypochlorite solution, cut with a cork borer to a thickness of $0.5 \mathrm{~cm}$ and a diameter of $13 \mathrm{~mm}$. Sliced potato discs were placed on agar plates $(1.5 \mathrm{~g} / 100 \mathrm{~mL})$. Agrobacterium tumefaciens A136 was incubated for 24-48 hours at $28^{\circ} \mathrm{C}$ in Luria Bertani Broth containing $50 \mu \mathrm{L}$ of tetracycline and $250 \mu \mathrm{L}$ of spectinomycin. The culture $(2 \mathrm{~mL})$ was mixed with $2 \mathrm{~mL}$ each of 10 , 100 and $1000 \mathrm{ppm}$ extract. $20 \mu \mathrm{L}$ of each mixture was added to the surface of the potato discs. After 21 days of incubation at $28^{\circ} \mathrm{C}$, all the discs were stained with Lugol's solution for 20 minutes, and the tumors were counted with a stereomicroscope. The tumor inhibition percentages of the extracts were calculated according to the following formula.

Percent inhibition: 100- $\frac{\text { The average number of tumors in the sample }}{\text { The average number of tumors in the control }}$ (Ramezani $\boldsymbol{e t}$ al., 2016)

\section{Statistical analysis}

Statistical calculations were carried out with the Minitab 17.0 software package. Descriptive statistics were applied to the findings, and it was determined whether the difference in the averages was significant $(\mathrm{P}<0.05)$, and a correlation test was applied to determine the relationship between the findings.

\section{RESULTS AND DISCUSSION}

\section{Antioxidant capacity and volatile compounds}

In the TEAC assay, the highest antioxidant capacity belonged to the methanol extract of Prunella vulgaris $(26.80 \pm 3.70 \mathrm{mmol}$ Trolox/g extract), while the lowest activity belonged to the ethanol extract of the branch of Sambucus nigra $(2.24 \pm 0.60 \mathrm{mmol}$ Trolox/g extract) (Table 1). The total phenolic content was the highest in the ethanol $(404.60 \pm 15.50 \mathrm{mg} \mathrm{GA} / \mathrm{g}$ extract) and methanol extracts (395.10 $\pm 13.20 \mathrm{mg} \mathrm{GA} / \mathrm{g}$ extract) of $S$. nigra, whereas the lowest was in the methanol $(163.42 \pm 6.08 \mathrm{mg} \mathrm{GA} / \mathrm{g}$ extract) and ethanol extracts $(118.88 \pm 5.81 \mathrm{mg}$ $\mathrm{GA} / \mathrm{g}$ extract) of Calendula officinalis flowers (Table 1). There was no significant difference between the extracts of the fruit of $S$. nigra in terms of antioxidant and total phenolic contents. In addition, there was no significant difference between the phenolic composition of the extracts, and the major components were benzeneacetaldehyde and palmitic acid. Passos da Silva $\boldsymbol{e t}$ al. (2017) stated that the berry extracts of S. nigra had a higher total phenolic content than the branch extract. Also in this study, antioxidant activity and total phenolic content were higher in fruits compared to branches. In another study, the total phenolic content of $S$. nigra was higher than the result obtained in this study (Akhtar and Mirza, 2018). The phenolic composition of $P$. vulgaris, which has the highest antioxidant capacity among the studied plants, was defined as propanamide, 2-hydroxy-N-ethyl-1,3-dithioisoindoline, dodecane, tetradecane, hexadecane, palmitic acid, ethyl palmitate, linoleic acid, and 7-pentadecyne. Unlike the ethanol extract, myristic acid, D-glycero-D-galacto-heptose, pentadecanoic acid, linolenyl alcohol, and stearic acid were identified in the 
methanol extract. Golembiovska et al. (2014) determined dodecane, tetradecane, hexadecane, myristic acid, pentadecanoic acid, and palmitic acid to be similar volatile components to our study. The methanol extract of $C$. officinalis had the highest antioxidant capacity $(16,9 \mathrm{mmol}$ Trolox/g extract) after $P$. vulgaris. $C$. officinalis contains sesquiterpene glycosides, saponins, xanthophylls, triol triterpenes, flavonoids, volatiles, $\alpha$-cadinene, $\alpha$-cadinol, and $\alpha$-muurolol, which show antioxidative and antimicrobial effects (Chaleshtori et al., 2016). In this study, $\alpha$-thujene and $\alpha$-pinene, D-limonene, $\alpha$-cubebene, $\alpha$-copaene, (-) isoledene, germacrene $\mathrm{D}$, alloaromadendrene, trans-caryophyllene, naphthalene, $\alpha$-humulene, (-)- $\beta$-selinene, $(+)$-ledene, dihydroactinidiolide, $\delta$-cadinene, dodecanoic acid, oplopenone, T-muurolol, $\beta$-eudesmol, t-cadinol, calendin, tetradecanoic acid, linoleic acid, methyl linolenate, tricosane, and eicosane were identified in the ethanolic extract of $C$. officinalis flowers. Additionally, $\alpha$ phellandrene, valencene, $\alpha$-guaiene, $\alpha$-muurolene, $\alpha$-longipinene, elemol, myristic acid, pentadecanoic acid, palmitic acid, linolenic acid, and stearic acid were defined in methanolic extract differently from ethanolic extract. Similarly, Caamal-Herrera et al. (2008) identified the major volatile constituents of hydroalcoholic extracts of $C$. officinalis flowers as $\alpha$-thujone and $\alpha$-cadinol

\begin{tabular}{|c|c|c|c|c|}
\hline Plant & Plant part & Solvent & $\begin{array}{l}\text { TEAC } \\
\text { (mmol trolox/g extract) }\end{array}$ & $\begin{array}{l}\text { TPC } \\
\text { (mg GA/g extract) }\end{array}$ \\
\hline P. vulgaris & whole plant & & $26.80 \pm 3.70^{*}$ & $377.30 \pm 12.70$ \\
\hline S. nigra & branch & $\mathrm{MeOH}$ & $4.10 \pm 2.20$ & $332.80 \pm 12.60$ \\
\hline S. nigra & fruit & & $10.40 \pm 6.40$ & $395.10 \pm 13.20$ \\
\hline C. officinalis & flower & & $16.90 \pm 4.80$ & $163.42 \pm 6.08$ \\
\hline P. vulgaris & whole plant & & $19.10 \pm 5.20$ & $336.45 \pm 7.27$ \\
\hline S. nigra & branch & $\mathrm{EtOH}$ & $2.24 \pm 0.60$ & $174.60 \pm 21.80$ \\
\hline S. nigra & fruit & & $10.90 \pm 3.90$ & $404.60 \pm 15.50$ \\
\hline C. officinalis & flower & & $12.30 \pm 4.20$ & $118.88 \pm 5.81$ \\
\hline
\end{tabular}

\section{Anti-quorum sensing activity}

Researchers are increasingly interested in medicinal herbal products to identify novel therapeutic and nonpathogenic agents that may act as nontoxic QS inhibitors to control infections without allowing the development of bacterial resistance (Bouyahya et al., 2017). Studies have shown that the virulence expression of pathogenic bacteria is based on quorum sensing systems as central regulators (Liu et al., 2017). It is known that various plants synthesize QS inhibitors by degrading QS signals or competing with signal receptors (Kalia $\boldsymbol{e}$ al., 2018). The ability of the extracts to inhibit communication between microorganisms (anti-quorum sensing) is shown in Figure 1.

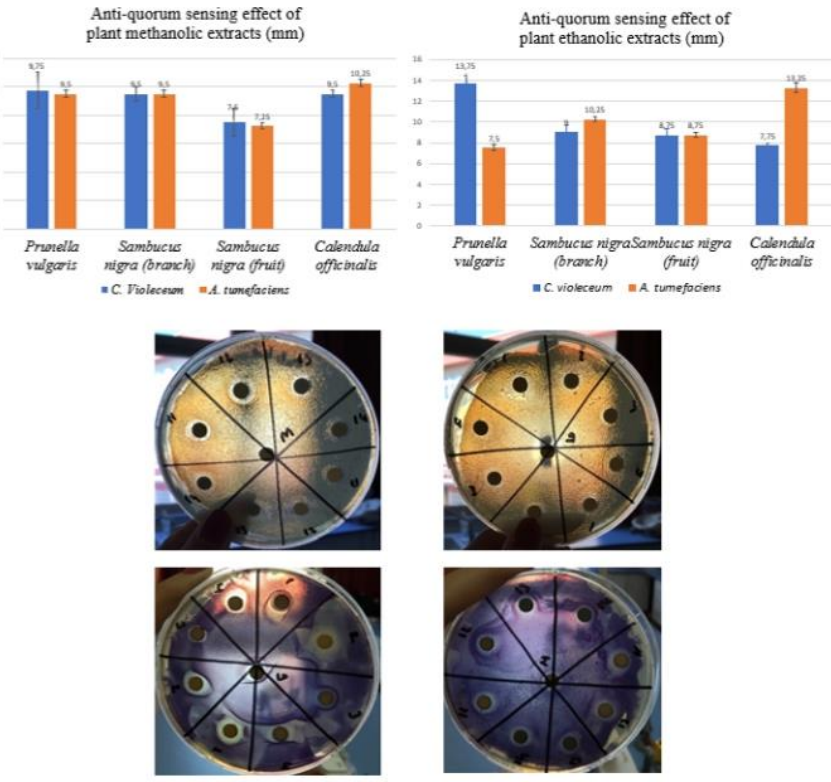

All plants in this study showed anti-QS activity. The methanolic extract of $P$ vulgaris exhibited $13.75 \mathrm{~mm}$ QS inhibition on CV026. Additionally, this inhibition zone was the highest observed zone among the studied plants. Koh and Tham (2011) determined the QS activity of the acetone-water extracts of 10 plants, including $P$. vulgaris. They reported that $P$. vulgaris formed a $15.5 \mathrm{~mm}$ QS inhibition zone, which is similar to our results. QS studies of other plants in our study have not been found in the literature. The lowest activity belongs to the methanolic extract of the fruit of $S$. nigra, and the inhibition zones for the other extracts varied between $8,75-13,75 \mathrm{~mm}$. The anti-quorum sensing activity of $S$. nigra has not been found in the literature, but it has been reported that Sambucus ebulus exhibits intense anti-quorum sensing activity against $S$. aureus (Quave et al., 2011). The most well-known mechanisms of plant extracts and phytochemicals are chemical structures similar to QS signals and their ability to damage signal receptors (Truchado et al., 2015). There are plants in the literature with higher QS activity than the plants studied in this study (Rubegeta et al, 2019; Liu et al., 2017). This difference is due to the phytochemical contents of those plants.

\section{Antibacterial activity}

The antibacterial activities of the extracts determined by the disc diffusion method against pathogenic bacteria are shown in Table 2. The ethanol extract of the branch of $S$. nigra produced the highest inhibition zone $(12.50 \pm 0.86 \mathrm{~mm})$ against $S$. aureus ATCC 25923. Hearst et al. (2010) observed that S. nigra leaves form a $6 \mathrm{~mm}$ zone against Bacillus cereus. In our study, the extracts formed zones ranging from $6.0-7.0 \mathrm{~mm}$ against B. cereus NCTC 7464. The reason for the low inhibition of the extract against Bacillus cereus may that these bacteria are spore-forming, so the antibacterial activity of the extract was insufficient. Hleba et al. (2013) found that the methanol extract of S. nigra forms a $13.5 \mathrm{~mm}$ zone against $E$. coli. In our study, the highest inhibition against $E$. col ATCC 8739 was obtained from the ethanol extract of the fruit with an $8.5 \mathrm{~mm}$ zone.

Figure 1 Anti-quorum sensing effect of the plant extracts

Table 2 Inhibition zones of the plant extracts against test culture

\begin{tabular}{|c|c|c|c|c|c|c|c|c|c|c|}
\hline Plant & Plant part & Solvent & $\begin{array}{c}\text { S. aureus } \\
\text { ATCC } \\
25923\end{array}$ & $\begin{array}{l}\text { S. aureus } \\
\text { RSSK } \\
9001\end{array}$ & $\begin{array}{c}\text { B.cereus } \\
\text { NCTC } \\
7464\end{array}$ & $\begin{array}{c}\text { B. subtilis } \\
\text { ATCC } \\
6633\end{array}$ & $\begin{array}{c}S . \\
\text { Typhimurium } \\
\text { ATCC } 14028\end{array}$ & $\begin{array}{l}\text { S. Enteritidis } \\
\text { ATCC 13076 }\end{array}$ & $\begin{array}{c}\text { E.coli } \\
\text { ATCC } \\
25922\end{array}$ & $\begin{array}{c}\text { E. coli } \\
\text { ATCC } \\
8739\end{array}$ \\
\hline P.vulgaris & whole plant & & n.s & $\mathrm{n}_{\mathrm{s}}$ & $6.7 \pm 0.75$ & $7.5 \pm 0.95$ & $6.5 \pm 0.50$ & n.s & n.s & $8.2 \pm 1.31$ \\
\hline S.nigra & fruit & & $9.5 \pm 1.06$ & $8.0 \pm 0.40$ & $6.7 \pm 0.75$ & $7.7 \pm 1.03$ & $8.2 \pm 0.62$ & $8.2 \pm 0.25$ & $7.7 \pm 1.03$ & $7.0 \pm 0.40$ \\
\hline C. officinalis & flower & $\mathrm{N}$ & $10.7 \pm 0.47$ & $10.2 \pm 0.25$ & $8.2 \pm 1.31$ & $7.2 \pm 0.75$ & $8.2 \pm 0.47$ & $7.7 \pm 1.03$ & n.s & $8.7 \pm 0.47$ \\
\hline P.vulgaris & whole plant & & $8.0 \pm 1.09$ & $7.0 \pm 1.60$ & $7.7 \pm 1.75$ & $10.5 \pm 1.72$ & $8.2 \pm 1.31$ & $9.7 \pm 1.17$ & $10.2 \pm 1.53$ & $8.5 \pm 1.50$ \\
\hline S. nigra & branch & & $12.5 \pm 0.86$ & $8.5 \pm 0.95$ & $6.7 \pm 0.75$ & $9.2 \pm 1.97$ & $8.0 \pm 0.40$ & $8.0 \pm 1.08$ & $8.2 \pm 1.31$ & $7.5 \pm 0.64$ \\
\hline S. nigra & fruit & & $8.5 \pm 1.44$ & $6.2 \pm 0.25$ & $7.0 \pm 1.00$ & n.s & $8.2 \pm 0.85$ & $8.0 \pm 0.81$ & $7.0 \pm 0.57$ & $8.5 \pm 0.50$ \\
\hline C. officinalis & flower & & $8.7 \pm 0.47$ & $10.0 \pm 0.40$ & $7.5 \pm 0.86$ & $6.7 \pm 0.47$ & $8.5 \pm 0.28$ & $7.7 \pm 1.03$ & n.s & $7.7 \pm 1.06$ \\
\hline ceftriaxone & & & $25.7 \pm 0.47$ & $24.5 \pm 1.50$ & $20.5 \pm 0.28$ & $30.0 \pm 0.40$ & $29.5 \pm 2.06$ & $31.7 \pm 1.49$ & $30.7 \pm 0.47$ & $31.25 \pm 1.49$ \\
\hline
\end{tabular}

* Values are expressed as the mean \pm standard deviation of three parallel measurements. $\mathrm{n} . \mathrm{s}$ : not sensitive at the tested concentration

MeOH: Methanol EtOH: Ethanol, Ceftriaxone: positive control 
However, the ethanol extract of $P$. vulgaris and the branch extract of $S$. nigra also showed a higher antibacterial effect on B. subtilis ATCC 6633, a spore-forming bacteria. The difference between the antibacterial activity of the extracts is due to the chemical structure or the antibacterial compounds having different concentrations in the content of the extracts and the differences between bacteria strains. Chaleshtori et al. (2016) found that the antimicrobial activity of $C$. officinalis essential oil was higher in Gram (-) bacteria than Gram (+) bacteria. In contrast to this study, $C$. officinalis extracts showed higher antibacterial activity against Gram (+) bacteria compared to Gram (-) bacteria in our study. This situation depends on several analytical, genetic, and environmental factors. The quantitative and qualitative values of secondary metabolites may show differences with genetic drift, physiological conditions, season, harvest time, as well as the method of analysis and sample preparation technique (Chen $\boldsymbol{e t}$ al. 2012). The MIC values of the extracts are shown in Table 3. The lowest MIC value $(3 \mathrm{mg} / \mathrm{mL})$ was determined against $S$. aureus RSSK 9001 from the ethanol extract of $P$. vulgaris. Mahboubi et al. (2015) determined the MIC value of $P$. vulgaris extract with ethanol as $3.2 \mathrm{mg} / \mathrm{mL}$ against $S$. aureus and $6.4 \mathrm{mg} / \mathrm{mL}$ against $B$. subtilis. These authors also found for a result of $12.8 \mathrm{mg} / \mathrm{mL}$ against $E$ coli. Our results are in parallel with this study. The $S$. nigra extracts had a lower inhibition concentration on Gram (-) bacteria that ranged from $12.5-25 \mathrm{mg} / \mathrm{mL}$ Mohammadsadeghi et al. (2013) determined the MIC values of the methano extract of $S$. nigra as $5 \mathrm{mg} / \mathrm{mL}$ for $S$. aureus and B. subtilis, $2.7 \mathrm{mg} / \mathrm{mL}$ for $E$. coli, and $1.9 \mathrm{mg} / \mathrm{mL}$ for $S$. Typhimurium. There was no correlation between the antioxidant capacity and total phenolic content of extracts in our study $(\mathrm{P}>0.5)$. Sengül et al. (2009) reached similar results. They explained that the determined antioxidant capacity is not only caused by phenolic compounds but also by other phytochemical components and the Folin-Ciocalteu method, which is used to determine the total phenolic substances and is not an absolute measurement.

Table 3 Minimum inhibitory concentration of the plant extracts $(\mathrm{mg} / \mathrm{mL})$

\begin{tabular}{|c|c|c|c|c|c|c|c|c|c|c|}
\hline Plant & $\begin{array}{l}\text { Plant } \\
\text { part }\end{array}$ & Solvent & $\begin{array}{c}\text { S. aureus } \\
\text { ATCC } \\
25923 \\
\end{array}$ & $\begin{array}{c}\text { S. aureus } \\
\text { RSSK } \\
9001 \\
\end{array}$ & $\begin{array}{c}\text { B.cereus } \\
\text { NCTC } \\
7464 \\
\end{array}$ & $\begin{array}{c}\text { B. subtilis } \\
\text { ATCC } \\
6633 \\
\end{array}$ & $\begin{array}{c}S . \\
\text { Typhimurium } \\
\text { ATCC } 14028 \\
\end{array}$ & $\begin{array}{c}S . \text { Enteritidis } \\
\text { ATCC13076 }\end{array}$ & $\begin{array}{l}\text { E.coli } \\
\text { ATCC } \\
25922\end{array}$ & $\begin{array}{c}\text { E. coli } \\
\text { ATCC } \\
8739\end{array}$ \\
\hline P.vulgaris & whole plant & & $6.0 \pm 0.01$ & $6.0 \pm 0.01$ & $12.5 \pm 0.01$ & $12.5 \pm 0.01$ & $6.0 \pm 0.01$ & $6.0 \pm 0.01$ & $12.5 \pm 0.01$ & $12.5 \pm 0.01$ \\
\hline S.nigra & fruit & МeOH & $12.5 \pm 0.01$ & $6.0 \pm 0.01$ & $25 \pm 0.01$ & $25 \pm 0.01$ & $12.5 \pm 0.01$ & $12.5 \pm 0.01$ & $25 \pm 0.01$ & $25 \pm 0.01$ \\
\hline C. officinalis & flower & & $12.5 \pm 0.01$ & $6.0 \pm 0.01$ & $25 \pm 0.01$ & $25 \pm 0.01$ & $25 \pm 0.01$ & $12.5 \pm 0.01$ & $25 \pm 0.01$ & $25 \pm 0.01$ \\
\hline P.vulgaris & whole plant & & $12.5 \pm 0.01$ & $3.0 \pm 0.01$ & $6.0 \pm 0.01$ & $6.0 \pm 0.01$ & $12.5 \pm 0.01$ & $25 \pm 0.01$ & $6.0 \pm 0.01$ & $6.0 \pm 0.01$ \\
\hline S. nigra & branch & FtOH & $12.5 \pm 0.01$ & $12.5 \pm 0.01$ & $12.5 \pm 0.01$ & $12.5 \pm 0.01$ & $25 \pm 0.01$ & $25 \pm 0.01$ & $12.5 \pm 0.01$ & $12.5 \pm 0.01$ \\
\hline S. nigra & fruit & EtUH & $6.0 \pm 0.01$ & $6.0 \pm 0.01$ & $25 \pm 0.01$ & $25 \pm 0.01$ & $12.5 \pm 0.01$ & $12.5 \pm 0.01$ & $25 \pm 0.01$ & $25 \pm 0.01$ \\
\hline C. officinalis & flower & & $12.5 \pm 0.01$ & $6.0 \pm 0.01$ & $25 \pm 0.01$ & $25 \pm 0.01$ & $25 \pm 0.01$ & $12.5 \pm 0.01$ & $12.5 \pm 0.01$ & $25 \pm 0.01$ \\
\hline
\end{tabular}

\section{Antitumor activity}

Medicinal and aromatic plants have been used to treat diseases since ancient years. Studies have focused on the pharmacological properties of medicinal plants, including antibacterial, antioxidant, antitumor, and bioactive products, such as essential oils, polyphenols, and flavonoids. It has been found that many plants used traditionally inhibit many bacteria and reduce tumor cells in cell lines and free radicals in the human body (Bouyahya et al., 2017). It has been discovered that secondary metabolites in plants such as terpenoids, phenolic acids, tannins, lignins, flavonoids, coumarins, and alkaloids show significant antioxidant activity and are essential in cancer treatment (Tagne et al., 2014) The antitumor activities of the extracts are shown in Figure 2.

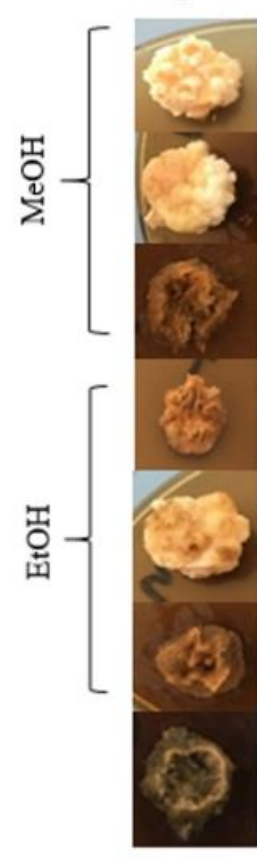

$\mathrm{MetOH}$

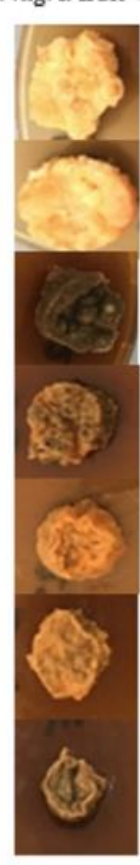

EtOH

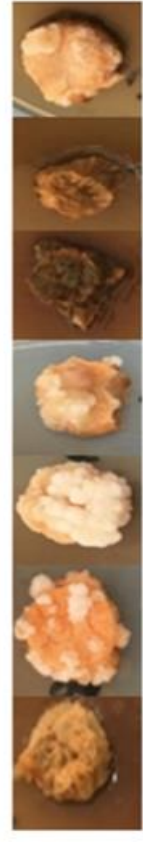

water
C. officinalis

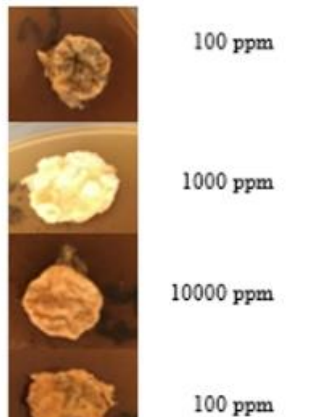

$1000 \mathrm{ppm}$

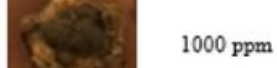

$10000 \mathrm{ppm}$

Control

Figure 2 Antitumor activity of the plant extracts

When the antitumor activities of the extracts were evaluated, there was a positive correlation between increasing concentration and percent inhibition. The extract with the highest tumor inhibition (76.2\%) at a concentration of $10000 \mathrm{ppm}$ was the ethanol extract of $P$. vulgaris, and the extract with the lowest activity $(44.7 \%)$ was the methanol extract of $C$. officinalis. In addition, the rankings of antioxidant capacity and total phenolic content were also the same for these plants. These results show that bioactive properties such as antitumor and antioxidant activity are derived from secondary metabolites in plant content.

Similarly, another study reported that a Fagonia cretica L. extract had a maximum tumor inhibition of $77.4 \%$, and its inhibition increased with increasing concentration (Hussain et al., 2007). In another study, Rumex hastatus D. Don chloroform and saponin fractions were reported to have $86.7 \%$ and $93.3 \%$ tumor inhibition (Ahmad et al., 2016). The difference in the tumorigenic approach of the extracts might be related to the profile of bioactive compounds. A value of $\geq 20 \%$ tumor inhibition is considered as an essential value for plant extracts (Ferrigni et al., 1982). As a result, the plants used in the study could be developed as a potential antitumor substance.

\section{CONCLUSION}

In this study, the usability of Prunella vulgaris, Sambucus nigra and Calendula officinalis as antimicrobial and antioxidant sources and their antitumor and antiquorum sensing properties were investigated. It has been demonstrated that the plants investigated in this study have functional properties and could be used in various industries including food, pharmaceutical and cosmetic. The intense black-purple color and antimicrobial, antioxidant properties of S. nigra increase the potential of being used as a natural food additive Bioactive properties of extracts can be increased by using different solvents and different extraction techniques. The effects of extract concentrations on organoleptic properties of foods should be investigated by sensory tests.

Acknowledgments:The authors thank to Assist. Prof. Dr. Dilvin Ipek, University of Canakkale Onsekiz Mart, Canakkale, Turkey, for providing the qs cultures (Agrobacterium tumefaciens A136, Chromobacterium violaceum 026) and supporting the determination of the plant anti-quorum sensing activity.

\section{REFERENCES}

Ahmad, S., Ullah, F., Ayaz, M., Zeb, A., Ullah, F., Sadiq, A. (2016). Antitumor and anti-angiogenic potentials of isolated crude saponins and various fractions of Rumex hastatus D. Don. Biological Research, 49(1), 18.https://doi.org/10.1186/s40659-016-0079-2

Akhtar, N., Mirza, B. (2018). Phytochemical analysis and comprehensive evaluation of antimicrobial and antioxidant properties of 61 medicinal plant species. Arabian Journal of Chemistry, 11(8), 1223-1235. https://doi.org/10.1016/j.arabjc.2015.01.013

Aydeniz, B., Yilmaz, E. (2012). Enrichment of frying oils with plant phenolic extracts to extend the usage life. European Journal of Lipid Science and Technology, 114(8), 933-941. https://doi.org/10.1002/ejlt.201100228

Bai, Y., Xia, B., Xie, W., Zhou, Y., Xie, J., Li, H., Liao, D., Lin, L., Li, C. (2016). Phytochemistry and pharmacological activities of the genus Prunella. Food Chemistry, 204, 483-496. https://doi.org/10.1016/j.foodchem.2016.02.047 Bouyahya, A., Bakri, Y., Khay, E. O., Edaoudi, F., Talbaoui, A., Et-Touys, A., Abrini, J., Dakka, N. (2017) Antibacterial, antioxidant and antitumor properties of Moroccan medicinal plants: a review. Asian Pacific Journal of Tropical Disease, 7(1), 57-64. https://doi.org/10.12980/apjtd.7.2017D6-294 
Burt, S. A., Reinders, R. D. (2003). Antibacterial activity of selected plant essential oils against Escherichia coli 0157: H7. Letters in Applied Microbiology, 36(3), 162-167. https://doi.org/10.1046/j.1472-765X.2003.01285.x Caamal-Herrera, I. O., Muñoz-Rodríguez, D., Madera-Santana, T., Antonio, J. (2008). Original Research Identification of volatile compounds in hydroalcoholic extracts of Calendula officinalis L. flowers and Mimosae tenuiflorae bark using GC/MS. International Journal of Applied Research in Natural Products, 9(1), 20-30.

Çetin, B., Kalyoncu, F., Kurtuluş, B. (2017). Antibacterial activities of Calendula officinalis callus extract. International Journal of Secondary Metabolite, 4(3, Special Issue 1), 257-263. https://doi.org/10.21448/ijsm.372108

Chaleshtori, S. H., Kachoie, M. A., Pirbalouti, A. G. (2016). Phytochemica analysis and antibacterial effects of Calendula officinalis essential oil. Biosciences and Biotechnology Research Communication, 9(3), 517-522. https://doi.org/10.21786/bbrc/9.3/26

Chen, Y., Zhu, Z., Guo, Q., Zhang, L., Zhang, X. (2012). Variation in concentrations of major bioactive compounds in Prunella vulgaris L. related to plant parts and phenological stages. Biological Research,45(2), 171-175. https://doi.org/10.4067/s0716-97602012000200009

Chenia, H. (2013). Anti-quorum sensing potential of crude Kigelia africana fruit extracts. Sensors, 13(3), 2802-2817. https://doi.org/10.3390/s130302802

Ferrigni, N. R., Putnam, J. E., Anderson, B., Jacobsen, L. B., Nichols, D. E., Moore, D. S., Smith Jr, C. R. (1982). Modification and evaluation of the potato disc assay and antitumor screening of Euphorbiaceae seeds. Journal of Natural Products, 45(6), 679-686. https://doi.org/10.1021/np50024a005

Golembiovska, O., Tsurkan, A., Vynogradov, B. (2014). Components of Prunella vulgaris L. Grown in Ukraine. Journal of Pharmacognosy and Phytochemistry, 2(6), 140-146.

Gopu, V., Kothandapani, S., Shetty, P. H. (2015). Quorum quenching activity of Syzygium cumini (L.) Skeels and its anthocyanin malvidin against Klebsiella $\begin{array}{llll}\text { pneumoniae. } & \text { Microbial } & \text { Pathogenesis, }\end{array}$ https://doi.org/10.1016/j.micpath.2015.01.010

Hearst, C., McCollum, G., Nelson, D., Ballard, L. M., Millar, B. C., Goldsmith C. E., Rooney, P. J., Loughrey, A., Moore, J. E., Rao, J. R. (2010). Antibacteria activity of elder (Sambucus nigra L.) flower or berry against hospita pathogens. Journal of Medicinal Plants Research,4(17), 1805-1809. https://doi.org/10.5897/JMPR10.147

Hleba, L., Kacániová, M., Petrová, J., Felsociová, S., Pavelková, A., Rovná, K. (2013). Antibacterial activity of some wild medical plants extract to antibiotic resistant Escherichia coli. The Journal of Microbiology, Biotechnology and Food Sciences, 2(1), 1215-1224

Hussain, A., Zia, M., Mirza, B. (2007). Cytotoxic and Antitumor Potential of Fagonia cretica L. Turkish Journal of Biology, 31(1), 19-24.

Hwang, Y. J., Lee, E. J., Kim, H. R., Hwang, K. A. (2013). In vitro antioxidan and anticancer effects of solvent fractions from Prunella vulgaris var. lilacina. BMC Complementary and Alternative Medicine, 13(1): 310 https://doi.org/10.1186/1472-6882-13-310

Islam, M. S., Akhtar, M. M., Rahman, M. M., Rahman, M. A., Sarker, K. K. Alam, M. F. (2009). Antitumor and phytotoxic activities of leaf methanol extract of Oldenlandia diffusa (willd.) roxb. Global Journal of Pharmacology, 3(2), 99106

Kalia, V. C., Patel, S. K., Kang, Y. C., Lee, J. K. (2019). Quorum sensing inhibitors as antipathogens: biotechnological applications. Biotechnology Advances, 37(1), 68-90. https://doi.org/10.1016/j.biotechadv.2018.11.006

Koh, K. H., Tham, F. Y. (2011). Screening of traditional Chinese medicinal plants for quorum-sensing inhibitors activity. Journal of Microbiology, Immunology and Infection, 44(2),

144-148.

https://doi.org/10.1016/j.jmii.2009.10.001

Larçin, Ö., Körpe, D. A., İşeri, Ö. D., Şahin, F. İ. (2016). Phenolic composition and antibacterial activity of crude methanolic Calendula officinalis flower extract against plant pathogenic bacteria. European Journal of Biology, 74(1), 25-33.

Liu. Z., Pan, Y., Li, X., Jie, J., Zeng, M. (2017). Chemical composition, antimicrobial and anti-quorum sensing activities of pummelo peel flavonoid

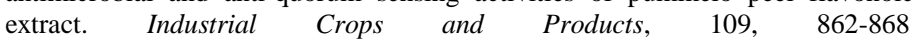
https://doi.org/10.1016/i.indcrop.2017.09.054

Mahboubi, M., Mahboubi, A., Kazempour, N. (2015). The antimicrobial activity of Prunella vulgaris extracts. Herba Polonica, 61(1), 31-38. https://doi.org/10.1515/hepo-2015-0008

Martin, D., Navarro del Hierro, J., Villanueva Bermejo, D., Fernández-Ruiz, R., Fornari, T., Reglero, G. (2016). Bioaccessibility and antioxidant activity of Calendula officinalis supercritical extract as affected by in vitro codigestion with olive oil. Journal of Agricultural and Food Chemistry,64(46), 88288837.https://doi.org/10.1021/acs.jafc.6b04313

McClean, K. H., Winson, M. K., Fish, L., Taylor, A., Chhabra, S. R., Camara M., Daykin, M., Lamb, J. H., Swift, S., Bycroft, B. W., Stewart, G. S., Williams P. (1997). Quorum sensing and Chromobacterium violaceum: exploitation of violacein production and inhibition for the detection of $\mathrm{N}$-acylhomoserine lactones. Microbiology, 143(12), 3703-3711 https://doi.org/10.1099/00221287143-12-3703
Mikulic-Petkovsek, M., Ivancic, A., Todorovic, B., Veberic, R., Stampar, F. (2015). Fruit phenolic composition of different elderberry species and hybrids. Journal of Food Science, 80(10), 2180-2190. https://doi.org/10.1111/1750 $\underline{3841.13008}$

Mohammadsadeghi, S., Malekpour, A., Zahedi, S., Eskandari, F. (2013). The antimicrobial activity of elderberry (Sambucus nigra L.) extract against gram positive bacteria, gram negative bacteria, and yeast. Research Journal of Applied Sciences, 8(4), 240-243. https://doi.org/10.36478/rjasci.2013.240.243

Mubashar Sabir, S., Khan, M. F., Rocha, J. B. T., Boligon, A. A., Athayde, M. L. (2015). Phenolic Profile, Antioxidant Activities and Genotoxic Evaluations of Calendula officinalis. Journal of Food Biochemistry,39(3), 316-324 https://doi.org/10.1111/jfbc.12132

Nalbant, D. (2017). Comparison of characteristic properties of some probiotic products made by using cow and goat milk [master dissertation]. Canakkale Onsekiz Mart University.

NIST. (2008). NIST-/EPA-/NIH Mass Spectral Library (NIST 08). Nationa Institute of Standards and Technology Standard Reference Data Program, Gaithersburg, MD 20899.

Pan, L., Chai, H., Kinghorn, A. D. (2010). The continuing search for antitumor agents from higher plants. PhytochemistryLetters, 3(1), 1-8. https://doi.org/10.1016/j.phytol.2009.11.005

Passos da Silva, D., Schofield, M., Parsek, M., Tseng, B. (2017). An update on the sociomicrobiology of quorum sensing in Gram-negative biofilm development. Pathogens, 6(4), 51. https://doi.org/10.3390/pathogens6040051

Quave, C. L., Plano, L. R., Bennett, B. C. (2011). Quorum sensing inhibitors of Staphylococcus aureus from Italian medicinal plants. Planta Medica, 77(02), 188-195. https://doi.org/ 10.1055/s-0030-1250145

Ramezani, M., Ehtesham-Gharaee, M., Khazaie, M., Behravan, J. (2016) Satureja hortensis L. Methanolic Extract and Essential Oil Exhibit Antitumor Activity. Journal of Essential Oil Bearing Plants, 19(1), 148-154. https://doi.org/10.1080/0972060X.2015.1060872.

Rasool, R., Ganai, B. A., Kamili, A. N., Akbar, S., Masood, A. (2010) Antioxidant and antibacterial activities of extracts from wild and in vitro-raised cultures of Prunella vulgaris L. Medicinal and Aromatic Plant Science Nad Biotechnology, 4, 20-27.

Rubegeta, E., Ahmad, A., Kamatou, G. P. P., Sandasi, M., Sommerlatte, H., Viljoen, A. M. (2019). Headspace analysis, antimicrobial and anti-quorum sensing activities of seven selected African Commiphora species. South African Journal of Botany, 122, 522-528. https://doi.org/10.1016/j.sajb.2018.03.001

Sengul, M., Yildiz, H., Gungor, N., Cetin, B., Eser, Z., Ercisli, S. (2009). Total phenolic content, antioxidant and antimicrobial activities of some medicinal plants. Pakistan Journal of Pharmaceutical Sciences, 22(1), 102-106.

Spanos, G. A., Wrolstad, R. E. (1990). Influence of processing and storage on the phenolic composition of Thompson seedless grape juice. Journal of Agricultural and Food Chemistry, 38(7), 1565-1571.

Tagne, R. S., Telefo, B. P., Nyemb, J. N., Yemele, D. M., Njina, S. N., Goka, S M. C., Lienou, L. L., Kamdje, A. H. N., Moundipa, P. F., Farooq, A. D. (2014) Anticancer and antioxidant activities of methanol extracts and fractions of some Cameroonian medicinal plants. Asian Pacific Journal of Tropical Medicine, 7 442-447. https://doi.org/10.1016/S1995-7645(14)60272-8

Thole, J. M., Kraft, T. F. B., Sueiro, L. A., Kang, Y. H., Gills, J. J., Cuendet, M. Pezzuto, J. M., Seigler, D. S., Lila, M. A. (2006). A comparative evaluation of the anticancer properties of European and American elderberry fruits. Journal of Medicinal Food, 9(4), 498-504. https://doi.org/10.1089/jmf.2006.9.498

Truchado, P., Larrosa, M., Castro-Ibáñez, I., Allende, A. (2015). Plant food extracts and phytochemicals: their role as quorum sensing inhibitors. Trends in Food Science \& Technology, 43(2), 189-204. https://doi.org/10.1016/j.tifs.2015.02.009

Veberic, R., Jakopic, J., Stampar, F., Schmitzer, V. (2009). European elderberry (Sambucus nigra L.) rich in sugars, organic acids, anthocyanins, and selected polyphenols. Food Chemistry, 114(2): https://doi.org/10.1016/i.foodchem.2008.09.080

Wiley. (2005). Wiley Registry of Mass Spectral Data 7. Edition (Fred. W. McLafferty) ISBN: 978-0471473251, (CD-ROM).

Zhang, G., He, L., Hu, M. (2011) Optimized ultrasonic-assisted extraction of flavonoids from Prunella vulgaris L. and evaluation of antioxidant activities in vitro. Innovative Food Science \& Emerging Technologies, 12(1), 18-25. https://doi.org/10.1016/j.ifset.2010.12.003 